\title{
B-Chronic Lymphocytic Leukemia Autophagyc Cell Death by the Use of Manganese Doped Zinc Oxide Nanoparticles and Photo- Dynamic Therapy.
}

\author{
Peña Luengas Sandra ${ }^{1, *}$, Marín Gustavo H. ${ }^{2}$, Rodríguez Nieto Felipe ${ }^{3}$, Dreon Marcos ${ }^{4}$, \\ Roque Gustavo $^{5}$, Núñez Luis ${ }^{1}$, Sanchez Fransisco ${ }^{6}$, Tarditti Adrian ${ }^{5}$, Schinella Guillermo ${ }^{2}$, \\ Pistaccio Luis ${ }^{5}$, Goya Rodolfo ${ }^{4}$, Tau Jose Maria ${ }^{5}$, Ichim Thomas ${ }^{7}$, Riordan Neil ${ }^{7}$, Rivera- \\ Montalvo Luis ${ }^{1}$, Mansilla Eduardo ${ }^{5}$. \\ ${ }^{I}$ Department of Chemistry, University of Puerto Rico, Mayaguez, Puerto Rico. \\ ${ }^{2}$ Department of Pharmacology, School of Medical Sciences, National University of La Plata, Argentina. \\ ${ }^{3}$ Department of Chemistry, Jauretche University, Florencio Varela, Buenos Aires, Argentina. \\ ${ }^{4}$ INIBIOLP, School of Medical Sciences, National University of La Plata, Argentina \\ ${ }^{5}$ Tissue Engineering, Regenerative Medicine and Cell Therapies Laboratory, CUCAIBA, La Plata, Argentina. \\ ${ }^{6}$ School of Physics, National University of La Plata, Argentina. \\ ${ }^{7}$ Medistem, San Diego, CA, USA
}

Available Online: 1st January, 2015

\begin{abstract}
B-Chronic Lymphocytic Leukemia (B-CLL) usually follows an adverse, relentless clinical course by slowly developing drug resistance to fludarabine and other chemotherapeutic agents, as well as by acquiring new different genetic abnormalities. As B-CLL cells spontaneously produce high amounts of Reactive Oxygen Species (ROS) having an altered redox state in relation to that of normal B lymphocytes, we decided to probe different metal Zinc nanoparticles (ZnNPs) and quantify the levels of Singlet Oxigen (SO) to see if variations of its intracellular concentrations could execute and accelerate deadly programs in leukemic cells rather than in normal B lymphocytes, when applied with Photodynamic Therapy (PDT). In this way, we developed and tested a variety of metal ZnNPs of which one made of 0.5\% Manganese Doped Zinc Oxide (ZnO:Mn) was finally selected for further testing as it had the best fludarabine resistant B-CLL cells in vitro killing activity, specially when combined with PDT. An interesting and rapidly dying process of B-CLL cells, known as autophagy, was always seen under Transmission Electronic Microscopy (TEM) when incubated with these $0.5 \% \mathrm{Mn}$ doped $\mathrm{ZnO}$ NPs. This phenomenon correlated well with those intracellular increases of SO when PDT was administered, and measured by a novel method first described by us. As this therapy seems to be very specific to fludarabine resistant B-CLL cells, producing almost no damage to normal lymphocytes, it could surely contribute in the near future as a new innovative targeted strategy to be delivered in the clinical setting for the definitive benefit of these bad prognostic patients.
\end{abstract}

\section{INTRODUCTION}

B-CLL and other chronic indolent hematologic malignancies like B lymphomas, are diseases which usually originate from hematopoietic $B$ cells with abnormal alterations in the processes of development, maturation and/or apoptosis. They usually manifest as progressive accumulations of morphologically mature B lymphocytes although immunologically dysfunctional ${ }^{1}$. $\mathrm{B}-\mathrm{CLL}$ is the most common adult leukemia in the western world and currently it has no available curative strategy ${ }^{2}$. Chemotherapy is still a valid alternative for its temporary improvement or just for tumor mass reduction, but not for a definitive healing treatment modality ${ }^{3}$. Gompertz's , as well as Goldie \& Coldman and Skipper concepts, have resulted in an enormous contribution to plan the administration of various antineoplastic drugs ${ }^{4,5}$. We have learned from them, about the importance of associating different drugs to avoid drug resistance. But this treatment approach usually leads to many complications and severe adverse effects for the patients ${ }^{6,7}$. New drugs, monoclonal antibodies as well as many other biologics have shown real improvements as anti-neoplastic therapies $^{8,9}$, but in general, the side effects are still also frequent and the development of resistance or relapse are usually inevitable in this type of diseases ${ }^{10-12}$. The gold standard of any oncologyc drug should be to submit the malignant cells to an apoptotic or cytotoxic program, without involving healthy ones, thereby minimizing adverse effects and maximizing the expected results, specially in those situations in which drug resistance has developed $^{13-15}$. Therefore, it is essential to think of new therapeutic modalities in order to increase the needed pharmacolocical effects, providing greater biological activity and much more specificity for diseases like B- 


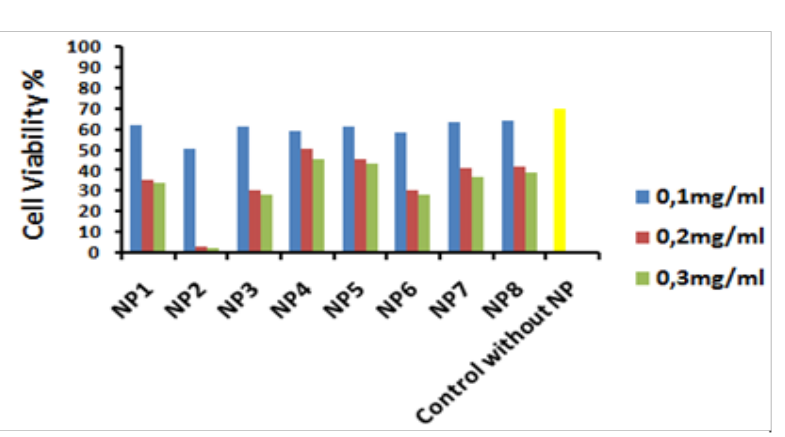

Fig 1. Effect of three different doses of each of the 8 NPs tested on the viability of B-CLL cells at 48 hs. of incubation after PDT. $0.2 \mathrm{mg} / \mathrm{ml}$ produced the most intense killing activity. Increasing this dose up to 0.3 $\mathrm{mg} / \mathrm{ml}$ did not produce further significant increase in cell mortality as seen with $0,2 \mathrm{mg} / \mathrm{ml}$.

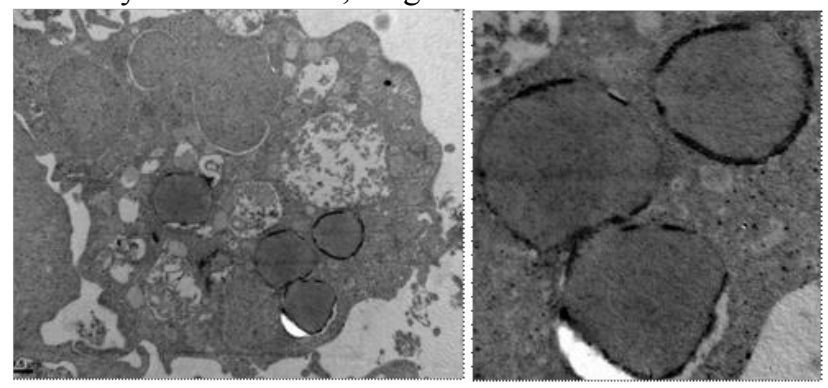

Fig 3. TEM images in which formation of double membrane bound organelles in B CLL cells is observed when treated with $0.5 \%$ Manganese doped ZnO NPs and PDT. These organelles are autophagosomes and the cell dying process undoubtly is Autophagy.

CLL. Nanotechnology, the science that studies, develops and employs nanometer-scale complex systems, has claimed to be the key to improve treatment outcomes in oncology ${ }^{16-18}$. Then, NPs, objects of a size of tens to

hundreds of nanometers, constructed with different materials such as natural or synthetic polymers or even metals, could be custom designed almost for every disease including B-CLL and other lymphomas ${ }^{19-21}$.

These elements when made of $\mathrm{ZnO}$ are plausible to be coated and modified by other elements and generate apoptotic and/or cytotoxic changes in malignant cells especially in the shape of autophagy. This specialized way of tumor cell death seems to be the specific result of metal NPs action and could be an interesting and innovative mechanism to be full discovered and achieved in cancer treatment ${ }^{22-24}$. ZnO NPs doped with metals such as $\mathrm{Mn}$ may have their optical and electronic properties modified as Mn is known to increase these NP's surface defects, thus generating photo-oxidation reactions that could be enhanced by PDT ${ }^{25-27}$. These NPs, if excited by the correct light emission may generate ROS specially SO that could lead to an induced apoptotic process or some other kind of death pathway like autophagy in BCLL cells, including those with resistant phenotypes to conventional therapies ${ }^{2,3}$. This strategy could be a very specific one, considering that the level of oxidative stress

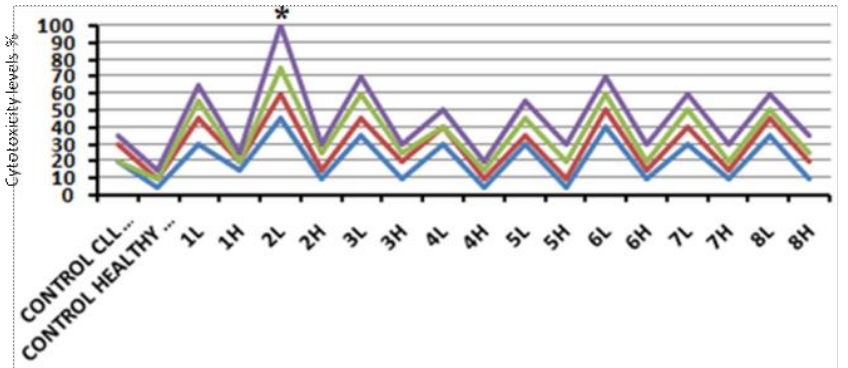

24 hs without irradiation- 24 hs with irradiation - $48 \mathrm{~h}$ s without irradiation $-48 \mathrm{hs}$ with irradiation

Fig 2. Cytotoxicity levels of B-CLL cells (L) from 5 patients and Normal B Lymphocytes (H) from 5 healthy donors for each NP at 24 and $48 \mathrm{~h}$ with and without laser irradiation. Clearly the most intense mortality is observe in B-CLL cells exposed to NPs2 at 48 hs and laser irradiated.

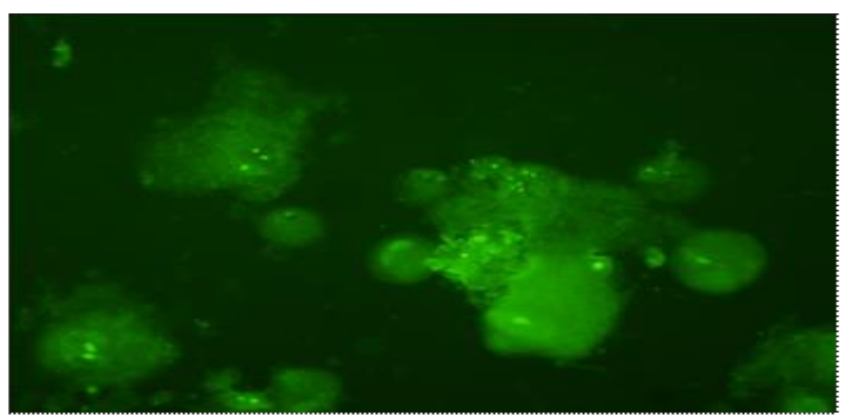

Fig 4. B-CLL cells incubated during two hours with SOSG and observed under fluorescent microscopy

found in leukemic cells is supposed to be a lot much higher than that of normal B lymphocytes ${ }^{28,29}$. Based on a growing body of evidence, ROS production is proposed as a key cytotoxic mechanism mediated by $\mathrm{ZnO}$ NPs leading to cell death ${ }^{30,31}$. Photo-activation of these $\mathrm{ZnO}$ NPs is predicted to induce greater levels of ROS including intracellular SO release which, if effectively targeted to cancer cells, could produce their selective final destruction ${ }^{26,27}$. Measurement of SO in biological environments is a major task specially when intracellular values, without interferences from the external medium, are required. Near-infrared (NIR) luminescence at 1270 $\mathrm{nm}$ in cell environments is confounded by the strongly reduced SO lifetime and probably had never been achieved until a research group developed a NIRsensitive photomultiplier tube probe that allowed to clearly identify and measure a true intracellular component of SO signal ${ }^{32,33}$. All these few described methods are expensive and required of a complex technology to be performed. PDT is a clinically tested promising technique to treat cancer. PDT uses light to activate light-sensitive drugs (photosensitizers) to produce short lived cytotoxic species such as SO to destroy malignant cells $\mathrm{s}^{34,35}$ and could be associated therapeutically with $\mathrm{NPs}^{17,18}$ for this pourpose. In this way, it was thought that NPs made of $\mathrm{ZnO}$ in 


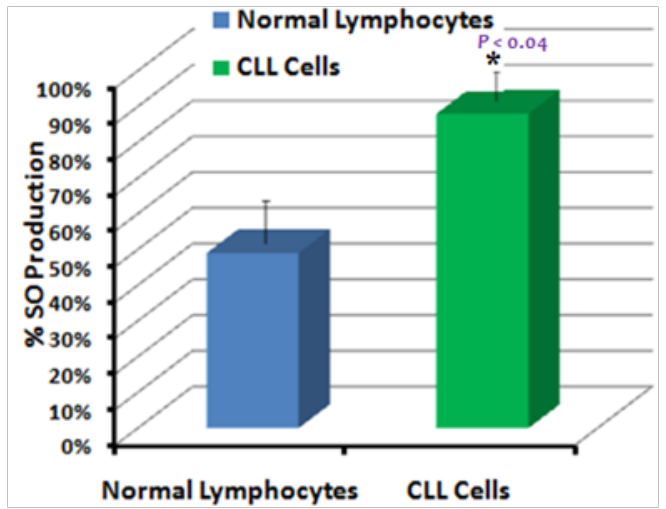

Fig 5. (a) Quantitative comparison of the intracellular SO generation after PDT by a fluorescent probe SOSG between normal lymphocytes and B-CLL cells from 5 healthy donors and 5 CLL patients treated with $0.5 \% \mathrm{Mn}$ doped $\mathrm{ZnO}$ NPs.

\begin{tabular}{|l|l|l|}
\hline SOSG QY & Lymphocytes & B-CLL Lymphocytic cells \\
\hline$Z n O: \mathrm{Mn}^{+2} 0.5 \%$ doping with HSA & 0.49 & 0.88 \\
\hline
\end{tabular}

Fig 5. (b) Singlet oxygen Sensor Green (SOSG) Quantum Yield (QY) of Mn 0.5\% doped ZnO NPs inside Normal Lymphocytes and B-CLL cells

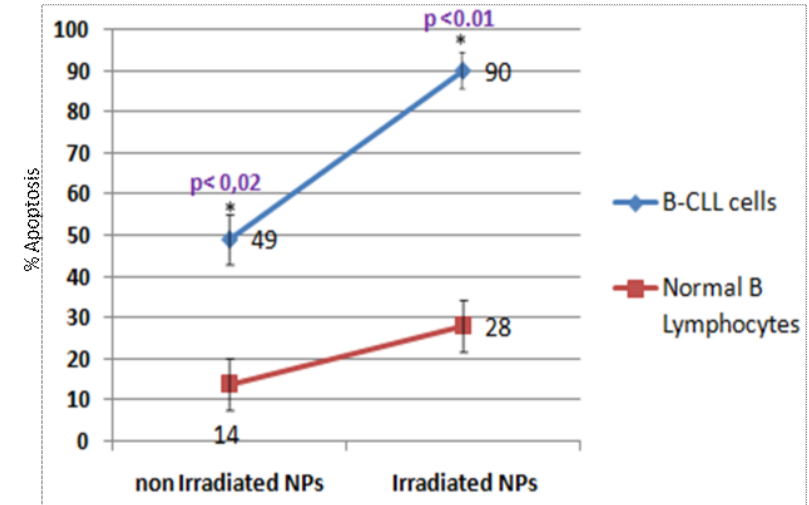

Fig 7. Apoptosis levels for Irradiated and Non-Irradiated B-CLL Cells and Normal B Lymphocytes Cultured with $0.5 \% \mathrm{Mn}$ doped $\mathrm{ZnO}$ NPs (NPs \#2) at 24 hs detected by flow cytometric analysis (annexin V/PI double staining)

combination with PDT, could be used to promote cytotoxic specific effects on B-CLL cells but specially on those resistant to conventional therapies.

\section{MATERIALS AND METHODS}

Procurement and Manipulation of Cells: B-CLL cells from 5 patients (L), with un-mutated Ig VH, known to be clinical resistant to fludarabine ${ }^{7,14}$, as well as normal B lymphocytes from 5 healthy subjects $(\mathrm{H})$, were obtained after informed consent. Both types of cells ( $\mathrm{L}$ and $\mathrm{H}$ ) were isolated from blood samples by density gradient centrifugation, using a Ficoll-Hypaque separation technique followed by a highly specific purifying method using a B Cell Isolation Kit developed for the fast and efficient separation of untouched B cells from human PBMCs by negative selection. This is an indirect

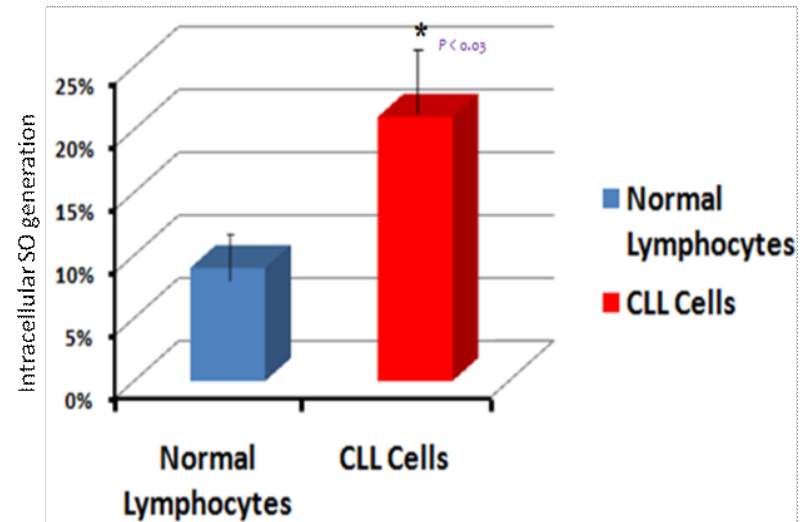

Fig 6(a). Quantitative comparison of the intracellular SO generated after PDT by fluorometry quantitative analysis of photooxidation reactions using DPBF as quencher between normal lymphocytes and B-CLL cells penetrated by $\mathrm{Mn} 0.5 \%$ doped $\mathrm{ZnO}$.

\begin{tabular}{|l|l|l|}
\hline SO QY & Lymphocytes & $\begin{array}{l}\text { B-CLL Lymphocytic } \\
\text { cells }\end{array}$ \\
\hline $\begin{array}{l}\mathrm{ZnO}: \mathrm{Mn}^{+2} 0.5 \% \text { doping with HSA } \\
(0.2 \mathrm{mg} / \mathrm{mL})\end{array}$ & 0.10 & 0.21 \\
\hline
\end{tabular}

Fig 6. (b) Singlet oxygen (SO) Quantum Yield (QY) generated in Normal Lymphocytes and B-CLL cells penetrated by $\mathrm{Mn} 0.5 \%$ doped $\mathrm{ZnO}$ after PDT.

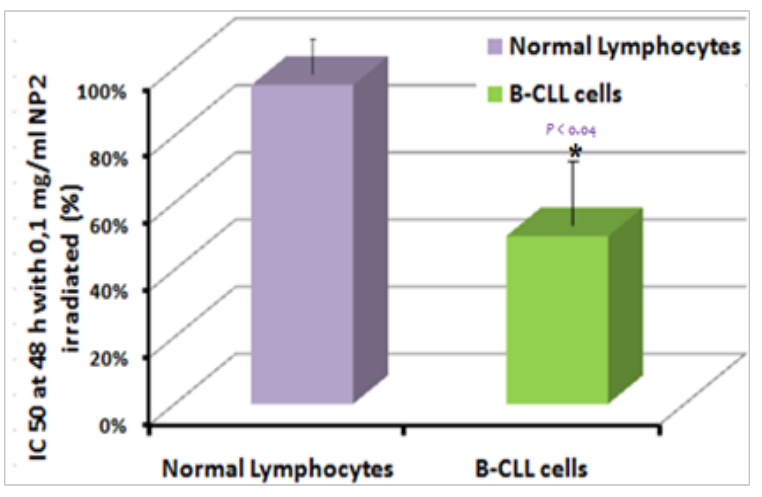

Fig 8. Comparison of the mean $\mathrm{IC}_{50}$ of $0.5 \% \mathrm{Mn}$ doped $\mathrm{ZnO}$ NPs on B-CLL cells $(\mathrm{n}=5)$ and normal B lymphocytes $(n=5)$.

magnetic labeling system. Non-B cells, for example, $\mathrm{T}$ cells, NK cells, dendritic cells, monocytes, granulocytes, and erythroid cells, are indirectly magnetically labeled by using a cocktail of biotin- conjugated antibodies against CD2, CD14, CD16, CD36, CD43, CD235a (Glycophorin A), and Anti-Biotin Micro-Beads. Isolation of highly pure $B$ cells is achieved by depletion of magnetically labeled cells using MACS ${ }^{\circledR}$ columns (Miltenyi Biotec $\mathrm{GmbH}$ ) [36][37][38]. Cells were then incubated at a concentration of $2 \times 10^{6}$ cells $/ \mathrm{ml}$ in RPMI 1640 medium with $10 \%$ Fetal Bovine Serum (FBS) (Invitrogen) at 5\% CO2 and $37^{\circ} \mathrm{C}$ overnight, before NPs testing was started. The next morning, $2 \times 10^{6}$ cells $/ \mathrm{ml}$ of medium were harvested to determine basal apoptosis and/or viability. Cells not exposed to NPs served as controls in every experiment. After this testing cells were incubated with NPs at 
different concentrations and times for all the penetration and mortality/viability experiments. Viability as well as degree of mortality/apoptosis of both cells, malignant and normal, were measured by the use of vital dyes staining techniques and fluorescence microscopy observation, MTT (4,5dimethylthiazol-2-5diphenyltetrazolium) probes and flow cytometry, as will be explained with more details later on.

Synthesis of NPs: Eight different types of Zinc (Zn) NPs were synthesized by different methods as described here: NP1 Zinc Oxide (ZnO), NP2 ZnO:Mn 0.5\%, NP3 ZnO:Mn 1.0\%, NP4 ZnO:Mn 1.5\%, NP5 ZnO:Mn 2.0\%, NP6 Zinc Sulfide (ZnS), NP7 ZnS:Mn 1.0\% and NP8 $\mathrm{ZnO} / \mathrm{ZnS}$. NPs were finally diluted and prepared for all experiments by vigorous sonication and addition of human serum albumin (HSA/ Sigma-Aldrich) at 1.5 $\mathrm{mg} / \mathrm{ml}$ to de-agglomerate them ${ }^{39}$.

Synthesis of ZnO and Mn-doped ZnO NPs: These NPs were synthesized via wet-chemical techniques ${ }^{40,41}$. Briefly, $4 \mathrm{mmol}$ of $\mathrm{Zn}$ acetate dihydrate were dissolved in $40 \mathrm{ml}$ of ethanol and heated at $50^{\circ} \mathrm{C}$ with intense stirring for 30 minutes and this was the precursor " $\mathrm{A}$ ". Then 4 mmol of sodium hydroxide were dissolved in $40 \mathrm{ml}$ of ethanol and heated at $50^{\circ} \mathrm{C}$ along with vigorous stirring for 1 hour, making in this way precursor " $\mathrm{B}$ ". $0.02 \mathrm{mmol}$ of manganese acetate (dopant) were dissolved in $40 \mathrm{ml}$ of ethanol at $50^{\circ} \mathrm{C}$ along with vigorous stirring for 30 minutes to produce precursor "C". $20 \mathrm{ml}$ of precursor "A" was then mixed with $20 \mathrm{ml}$ of precursor "C". Both solutions were heated at $80^{\circ} \mathrm{C}$ for 30 minutes. After cooling $20 \mathrm{ml}$ of precursor " $\mathrm{B}$ " were then added to the mixed solution with constant stirring. The new solution was kept in an oil bath at $65^{\circ} \mathrm{C}$ for 2 hours. After cooling for 4 hours, the solution was centrifuged for 20 minutes at $4000 \mathrm{rpm}$. The precipitate was washed and dried. The different Mn doping percentages applied on the surface of NPs were $0.5,1.0,1.5$ and $2.0 \%$. Un-doped $\mathrm{ZnO}$ NPs were synthesized with a similar procedure except for the addition of manganese acetate ${ }^{40,41}$. (Zinc acetate dihydrate, sodium sulfide non-hydrate, manganese acetate tetrahydrate and sodium hydroxide were all purchased from Sigma-Aldrich).

Synthesis of colloidal ZnS semiconductor nano-crystals capped with poly-vinylpyrrolidone (PVP) and prepared using $1 \%$ concentration of $M n+2$ ion as a dopant: The NPs were synthesized via wet-chemical techniques ${ }^{42,43}$. Aqueous solution of $1.0 \mathrm{M} \mathrm{Zn}$ acetate dihydrate, $0.85 \mathrm{M}$ sodium sulfide nonahydrate, and 0.010 $\mathrm{M}$ manganese (II) acetate tetrahydrate were prepared. $0.56 \mathrm{~g}$ of poly(vinylpyrrolidone) (PVP) was dissolved in $5 \mathrm{~mL}$ of the zinc acetate obtaining a concentration of $1.0 \mathrm{M} .5 \mathrm{~mL}$ of the manganese acetate solution was added to this solution. $5 \mathrm{~mL}$ of the sodium sulfide solution was then added slowly with stirring, thereby precipitating the nanoparticles. The solution was centrifuged for 10 minutes at $3000 \mathrm{rpm}$ and washed with deionized water. The nano-crystals were re-dispersed in water to make a $0.01 \mathrm{M}$ solution. Un-doped ZnS NPs were synthesized with a similar procedure except for the addition of manganese acetate ${ }^{42,43}$. (Zinc acetate dihydrate, sodium sulfide nonahydrate, manganese (II) acetate tetrahydrate, poly(vinylpyrrolidone) were all purchased from SigmaAldrich).

Preparation of $\mathrm{ZnO} / \mathrm{ZnS}$ core shell NPs: The preparation of $\mathrm{ZnO} / \mathrm{ZnS}$ core shell NPs was performed by thermal decomposition of Zn-3-Mercaptopropionic acid (MPA) complexes $^{44,45}$. Briefly, $10 \mathrm{~mL}$ of a $0.1 \mathrm{M}$ zinc acetate dihydrate aqueous solution and $0.35 \mathrm{~mL}$ of MPA were mixed in a flask. This solution was diluted to $98 \mathrm{ml}$ with water, the $\mathrm{pH}$ adjusted to 10.3 with $4 \mathrm{M}$ sodium hydroxide $(\mathrm{NaOH})$ and satured with nitrogen $\left(\mathrm{N}_{2}\right)$ by bubbling for $20 \mathrm{~min}$. ZnO NPs were dispersed in water to obtain a concentration of $0.01 \mathrm{M}$ and diluted to $43 \mathrm{~mL}$ with water and purged with $\mathrm{N}_{2} .7 \mathrm{~mL}$ solution of $\mathrm{Zn}+2-\mathrm{MPA}$ complex was added drop-wise to $\mathrm{ZnO}$ QDs and the mixture refluxed for $6 \mathrm{~h}$. NPs were recovered by filtration and dried in an oven at $60^{\circ} \mathrm{C}$. (Zinc acetate dihydrate, 3Mercaptopropionic acid and sodium hydroxide were all purchased from Sigma-Aldrich).

Characterization of NPs: We decided to characterize in full detail only that type of NP with the best B-CLL cytotoxic effects when applying PDT and tested in vitro for viability and mortality of leukemic cells as later will be described. This further characterization was done by Transmission Electron Microscopy (TEM) (JEM-2100F, JEOL Inc.) and Scanning Electron Microcopy (SEM) (JEOL-JSM 6500 instrument and a Philips/ FEI, XL30s, FEG SEM / Phoenix EDAX) observation after deagglomeration of NPs with Human Serum Albumin (HSA) $1,5 \mathrm{mg} / \mathrm{ml}$ and intense sonication, as well as by elemental composition analysis by Energy dispersive $\mathrm{X}$ ray spectroscopy (EDS). Also, X-Ray Diffraction (XRD) measurements were carried out with a Diffractometer (D5000/Siemens) using $\mathrm{Cu}-\mathrm{K} \alpha$ radiation with $\lambda=0.154315 \mathrm{~nm}$ to determine the crystalline nature of the selected NPs. An UV-vis spectrophotometer (DU 800, Beckman Coulter) was used to study the optical absorption of NPs. Luminescence properties and SO generation by NPs was determined by photoluminescence (PL) spectroscopy, using a spectro-fluorometer (FluoroMax-2/Horiba Scientific) at room temperature with a $150 \mathrm{~mW}$ continuous ozone-free Xe lamp. Fouriertransformed infrared (FTIR) spectra was recorded using an attenuated total reflection Fourier Transform Infrared (FTIR-Varian 3100 FT-IR/Bio-Rad) to evaluate and characterized the presence of functional groups on the surface of these NPs.

Penetration of cells by NPs:0.1, 0.2 and $0.3 \mathrm{mg} / \mathrm{mL}$ of each of the eight NPs produced were incubated with $4 \times 10^{6}$ cells in $2 \mathrm{ml}$ of culture medium for a maximum period of three hours, under conditions already described. NPs penetration of cells was determined by TEM and by fluorescence microscopy (Motic Inverted Microscope AE30-31 with Episcopic-Fluorescence Attachment EFINV-II) using a DAPI filter. Degree of penetration was determined by 3 independent pathologists observers trained in cell observation with TEM by evaluation of 5 pictures taken at every each time point $(0,30,60,120$ and 180 minutes) of incubation of the cells with the different NPs and its selected concentrations mentioned before. 
For this purpose, cells with NPs were summited to two washing cycles and finally to a re-supension step in PBS before TEM observation was performed. Results were the mean of the penetration scores given by all the observers to the 5 pictures for each specific NP and its different concentrations at every time point. Finally the level of penetration was ranked in relation of the total cell surface covered with NPs as none (0-5\%), discrete (6-45\%), moderate $(46-75 \%)$ or intense $(76-100 \%)$ as seen in each TEM picture by each observer. The time at which the highest level of cell penetration by NPs occurred, was later used as the best time point for all laser irradiation experiments. When maximum NPs cell penetration was determined by TEM, confirmation of this data was done by observation of cells under fluorescence microscopy using a DAPI filter in which the cells were supposed to fluorescence when penetrated by NPs.

Photodynamic Therapy (PDT) Procedures: PDT was implemented by the use of a green laser (EVO Series-3BWicked Laser) with a wavelength of $532 \mathrm{~nm}$ and $75 \mathrm{mw}$ of power in order to irradiate the samples. The sample containing 4 million cells in $2 \mathrm{ml}$ of PBS was incubated with NPs and DPBF (1,3-diphenylisobenzofuran$\mathrm{DPBF} /$ Aldrich) as the chemical quencher ${ }^{46-48}$. The concentration of DPBF used in these probes was $6.0 \times 10-5$ $\mathrm{M}$ and for NPs it was that one that produced the most intense penetration of cells in previous experiments at the shortest time point. After the selected time for cell incubation with NPs and the quencher, the samples with a total volume of $2 \mathrm{ml}$ were mixed in a quartz cuvette and immediately irradiated with the laser light source. The light laser was kept constant at $40 \mathrm{~cm}$ from the samples in order to irradiate them inside a dark black box specially constructed for these purposes. This method used a standard photosensitizer of a known SO quantum yield. In our case we used Rose Bengal (RB) at 1.0x10-5 M with a high quatum yield (QY) of $\mathrm{SO}(\Phi \Delta=0.75)^{35,49,50}$. Then, SO quantum yields were determined by monitoring the disappearance of the quencher's bands from their respective photoluminescence spectra, using an excitation source of $410 \mathrm{~nm}$ under continuous irradiation. Fluorescence was measured with a spectro-fluorometer (FluoroMax2) with a $150 \mathrm{~mW}$ continuous ozone-free Xe lamp as the excitation source. Fluorescence data was collected every 2 seconds and up to a total time of 14 seconds of laser irradiation with a rest period between irradiations of 2 minutes to later correlate with all the viability tests done on both cells the B-CLL and the healthy ones. Cells were cultured and incubated either with NPs in 96 micro-wells plastic plates or in $2.5 \mathrm{ml}$ cryo-vials for 24 and/or 48 hours after irradiation as needed. Similarly we analyzed the variations of another fluorescent probe, Singlet Oxygen Sensor Green (SOSGMolecular Probes/Invitrogen) for the measurement of $\mathrm{SO}^{32,51}$. In this way again, 4 million leukemic or normal cells $/ 2 \mathrm{ml}$ of $\mathrm{PBS}$, were incubated with the selected concentration of NPs and $5 \mathrm{ul} / \mathrm{ml}$ of SOSG, during the selected incubation time and later on using an excitation/emission of 485-495 $\mathrm{nm}$ for its detection while all fluorescence data was recorded every minute and up to a total time of 7 minutes of laser irradiation, with a rest period between irradiations of 2 minutes.

Measurement of Intracellular Singlet Oxygen (SO) Production: For the measurement of intracellular SO production and its variations a novel and innovative method was thought and implemented by us. Briefly, determination of the intracellular SO generation quantum yield after incubation of both types of cells with NPs was done by fluorometry quantitative analysis of photooxidation reactions either using DPBF at $6.0 \mathrm{x} 10$ $5 \mathrm{M}$ as the quencher or SOSG at $5.0 \mu \mathrm{L} / \mathrm{mL}$ as a fluorescent probe for $\mathrm{SO}$, after the administration of PDT. Incubation of cells with SOSG was done for 2 and 3 hours followed by observation of its penetration inside cells by fluorescence microscopy and lightening of the cells for 10 minutes with the microscope's fluorescence lamp, using a double simultaneous Nikon filter for both FITC and DAPY. SOSG should make penetrated cells fluorescent under the lamp stimulation in the green color range similar to that of FITC. By doing this, we selected the best time period for incubation of cells with SOSG which was found to be 2 hours. Then, centrifugation of the cells was done in complete darkness for 40 minutes, followed by determination of the presence of any residual SOSG in the supernatants by fluoroscopic measurement. After this, re-suspension of the cells in

new PBS was done with centrifugation for another 30 minutes 2 more times, exchanging every time the supernatant by new PBS. Measurement of no residual SOSG was supposed to be reached in the final supernatant, or more cycles of washing and centrifugation were performed until no trace of SOSG could finally be found in it. At the end, re-suspension of cells in new PBS and measurement of intracelular emission at SOSG wavelength by fluoroscopy analysis was performed after PDT as mentioned before. The same procedure was then reproduced but using DPBF instead of SOSG, at a non toxic concentration for either kind of cell, observing and registering the changes in its levels, specially the decrease of its fluorescence emission intensity, in a time dependent manner.

Determination of Cell Viability and Mortality: To determine NPs and PDT effects on cell viability we used a vital dye staining technique with acridine orange/propidium iodine (Fluoroquench/One-Lambda) as well as MTT (4,5dimethylthiazol-25 diphenyltetrazolium) assays. In this way $2 \times 10^{5}$ cells were incubated in 200 ul of medium with FBS inside each of the 96 micro-wells of the mentioned plastic disposable sterile culture trays. Three concentrations, 0.1 , 0.2 and $0.3 \mathrm{mg}$ of each of the $8 \mathrm{NPs}$ per $\mathrm{ml}$ of medium, were used in all the cytotoxicity tests performed in B normal lymphocytes and B-CLL cells, using the described vital staining technique with Fluoroquench and fluorescence microscopy observation in which, dead cells were seen red and living ones green. Also MTT probes were used for these same purposes. Results were the mean of the mortality rates observed in the 5 healthy donors $(\mathrm{H})$ and the 5 leukemic patients $(\mathrm{L})$ cells tested and exposed to each of the 3 selected concentrations of 
each NP used. After the viability testing by Fluoroquench observation and MTT tests of all the 8 NPs on both types of cells, the one that could cause the greater mortality in B-CLL cells after PDT was chosen to continue all other experiments and characterizations. As soon as the most powerful cytotoxic NP was selected, its IC50 (the amount of that NP needed in vitro to kill $50 \%$ of the tested cells in a 24 hour incubation time) was determined by MTT and Flow Cytometry analysis. AnnexinV-fluorescein isothiocyanate (annexin V-FITC) and Propidium Iodine were used for Flow Cytometry (BD Becton-Dickinson FACS Verse) measurements of cell apoptosis and viability respectively. Cells were always centrifuged and re-suspended in PBS immediately before their use in the fluorometric measurements. Fluorometric analysis of the cell products with NPs were performed with a spectrofluorometer as mentioned before and always using a concentration of $2 \times 10^{6}$ cells $/ \mathrm{ml}$ of PBS in quarts cuvetts to a full volume of $2 \mathrm{ml}$ irradiated in a black dark box using the same green laser and irradiation times and distance already described in this paper. For fluoroscopy analysis a new method was thought and implemented by us as said before. In all experiments, control samples at each time point were collected and the NPs induced cell death was determined at 24 and 48 hs of culture. Also, measurement of free ion $\mathrm{Zn}$ after incubation of the selected NPs in ultrapure water for 72 hs was performed by a conventional method. In this way, it was planned to test in further cytotoxicity tests, the $\mathrm{Zn}$ concentration that could potentially be found as a consequence of NPs dissolution and see if $\mathrm{Zn}$ by itself and in those concentrations could be responsable for some of the killing activities on normal and/or B-CLL cells.

Statistical Analysis: Data were expressed as mean plus or minus the confidence interval $95 \%$ (CI). T test was used to compare the mean values of the different experimental groups and control samples treated with NPs with and without PDT. The one-way analysis of variance (ANOVA ) was used to compare the values of the control samples with sample time points of B-CLL cells at 24 and 48 hours of incubation with NPs. The flow cytometry histograms were obtained and analyzed with the software CellQuestPro. The correlation between the levels of SO and NPs2 cell sensitivity with and without laser irradiation was analyzed using Spearman correlation. P values less than 0.05 were considered statistically significant.

\section{RESULTS}

We first evaluated the effect of three different doses, 0.1 , 0.2 and $0.3 \mathrm{mg} / \mathrm{ml}$ of each of the 8 NPs produced by testing them for their penetration capacity into B-CLL cells as well as into normal B lymphocytes during a total culture period of 3 hours (Fig 1). NP1 as it has been said before corresponded to $\mathrm{ZnO}, \mathrm{NP} 2$ to $\mathrm{ZnO}: \mathrm{Mn}+20.5 \%$ doping, NP3 to $\mathrm{ZnO}: \mathrm{Mn}+2 \quad 1.0 \%$ doping, NP4 to $\mathrm{ZnO}: \mathrm{Mn}+2 \quad 1.5 \%$ doping, NP5 to $\mathrm{ZnO}: \mathrm{Mn}+2 \quad 2.0 \%$ doping, NP6 to ZnS, NP7 to ZnS:Mn+2 1.0\% doping and $\mathrm{NP} 8$ to $\mathrm{ZnO} / \mathrm{ZnS}$. The results of these experiments indicated that $0.2 \mathrm{mg} / \mathrm{ml}$ of each of the analyzed NPs, resulted in an intense cell penetration activity by all of them that was not further increased by its rising to a higher concentration of $0.3 \mathrm{mg} / \mathrm{ml}$. Because of this, the concentration of $0.2 \mathrm{mg} / \mathrm{ml}$ of NPs was used in all further experiments. At time 0 , no particles were seen inside any of the cells but at two hours time point all observers agreed there was a maximum "intense" similar penetration of all NPs in both type of cells . Normal lymphocytes as well as B-CLL cells were well and maximally penetrated by NPs at $0.2 \mathrm{mg} / \mathrm{ml}$ concentration when cultured at $37^{\circ} \mathrm{C}$ during two hours and observed under TEM . At three hours culture time no significant further increase in the amount of total NPs penetration into cells was observed either in leukemic or normal ones. B-CLL cells as well as normal B lymphocytes when incubated during this time period with $0.2 \mathrm{mg} / \mathrm{ml}$ of each of the NPs and observed under TEM and fluorescent microscopy were clearly and intensively penetrated by all of these NPs tested as described by the 3 observers and no increment of NPs penetration in cells was found after this time point as it was said. In this way an incubation period of 120 minutes with $0.2 \mathrm{mg} / \mathrm{ml}$ of NPs was selected as the best conditions for NPs penetration into cells. Then, we evaluated the effect of those same three different doses, $0.1,0.2$ and $0.3 \mathrm{mg} / \mathrm{ml}$ of each of the 8 NPs on the viability of both B-CLL cells and normal lymphocytes at 24 and 48 hours of incubation after PDT (Fig 1). In these probes $0.2 \mathrm{mg} / \mathrm{ml}$ of each of the NPs tested, again resulted in the best B-CLL cell killing activity. Normal Lymphocytes also had the greatest mortality rates at this NPs concentration but were always significantly lower and mostly insignificant in relation to that observed for B-CLL cells (Fig 2). It was also seen that $0.1 \mathrm{mg} / \mathrm{ml}$ of each $\mathrm{NP}$, had almost no significant difference in the viability of B-CLL cells in relation with that of the control samples without NPs except for NP2. Scaling up the NPs concentration to $0.3 \mathrm{mg} / \mathrm{ml} \mathrm{did} \mathrm{not}$ either significantly improved the cell killing activity of those same NPs in relation to that concentration of 0.2 $\mathrm{mg} / \mathrm{ml}$. Then this concentration of $0.2 \mathrm{mg} / \mathrm{ml}$ was selected and used for all other experiments. From the 8 NPs specially designed and produced for this study, $0.5 \%$ Mn-doped $\mathrm{ZnO}$ NPs, were chosen as the most powerful killing NPs against B-CLL cells when associated with PDT, but with minimum impact on normal lymphocytes. At the mentioned concentration of $0.2 \mathrm{mg} / \mathrm{ml}$, NPs2 ( $0.5 \% \mathrm{Mn}$ doped $\mathrm{ZnO} \mathrm{NPs})$ were the most effective NPs in relation to its killing activity of B-CLL cells (Fig 1). In this way NP2 was selected for the performance of all other characterization and cytotoxicity procedures. This type of NP had an absorbance spectrum with a well defined band at $364 \mathrm{~nm}$. They showed a predominant energy band-gap of 3.5 Ev.. The emission spectrum of these NPs had one weak band in the UV region around $397 \mathrm{~nm}$ that could be attributed to their band-gap as well as another broad one at $542 \mathrm{~nm}$ in the visible region which could be related to oxygen defects. Processes in which transitions with the photo-generated holes at the surface of the NPs are trapped by $\mathrm{O} 2$-ions are probably responsible for the visible emission of those NPs. Doping 
with Mn could increase these surface defects of NPs and improve the action of PDT.. X-Ray Diffraction (XRD) patterns of $\mathrm{ZnO}: \mathrm{Mn}+2$ NPs showed several peaks with $2 \Theta$ of $31.67^{\circ}, 34.31^{\circ}, 36.14^{\circ}, 47.40^{\circ}, 56.52^{\circ}, 62.73^{\circ}$, $66.28^{\circ}, 67.91^{\circ}$ and $69.03^{\circ}$ corresponding to (100), (002), (101), (102), (110), (103), (200), (112) and (201) planes), indicating an hexagonal wurtzite structure ${ }^{23,52}$. No additional peaks related to any other impurities were detected. The average crystallite size of these Mn doped ZnO NPs was calculated from the XRD patterns using Scherrer's formula [55], being $14.41 \pm 4.95 \mathrm{~nm}$. Fourier Transform Infrared (FTIR) spectrum of these $0.5 \% \mathrm{Mn}$ doped $\mathrm{ZnO}$ NPs confirm the formation of $\mathrm{Zn}-\mathrm{O}$ and $\mathrm{Mn}-$ $\mathrm{O}$ bonds in the crystal structure [52]. By scanning electron microscopy (SEM) and transmission electron microscopy (TEM) after being well de-agglomerated using HSA and intense sonication ${ }^{39}$, most of the NPs had spherical shapes with an average size of 20-25 nm. The resulting $0.5 \% \mathrm{Mn}$ doped $\mathrm{ZnO} \mathrm{NPs}$ morphology was quite similar in both analysis (TEM and SEM) being observed as an homogeneous population of NPs of that mentioned size. TEM and SEM images showed that the NPs, appeared a little larger in size than the same estimated result from Scherrer analysis. Energy dispersive $\mathrm{X}$ ray spectroscopy $(\mathrm{EDS})^{53,54}$ analysis of $\mathrm{ZnO}: \mathrm{Mn}+2$ NPs confirmed the elemental composition of these NPs. The presence of $\mathrm{Zn}$ and oxygen was demonstrated as was observed in the obtained corresponding EDS peaks. The presence of $\mathrm{Au}, \mathrm{Si}, \mathrm{Cl}, \mathrm{Ca}$ and $\mathrm{K}$ was probably due to interferences mixed while sample preparation. As observed by TEM both types of cells could undergo a process of cell death after $0.5 \% \mathrm{Mn}$ doped $\mathrm{ZnO}$ NPs treatment with or without PDT, corresponding to features of autophagy, but this phenomenon was always stronger when PDT was applied .This autophagic cell death was specially pronounced, much more advanced, massive and faster on B-CLL cells, affecting almost all of them treated in this way (Fig 3). In the other hand, normal B lymphocytes, only suffered autophagyc changes in a very lesser degree and basically in the form of an isolated pattern in which only few cells went through this dying pathway beside being treated in the same way and during the same period of time. In this scenario of autophagy, the formation of doublemembrane bound organelles predominated in B-CLL cells when treated with $0.5 \% \mathrm{Mn}$ doped $\mathrm{ZnO}$ NPs alone but predominantly when PDT was simultaneously applied. These organelles were clearly autophagosomes and by this specific detail the observed dying process can undoubtedly be considered as autophagy (Fig 3), which denotes any cellular pathway involving the delivery of cytoplasmic material to the lysosome for degradation ${ }^{55-57}$. Changes in the production of intracellular SO was detected in both normal and B-CLL cells after being penetrated by NPs and laser irradiated. But the increase of intracellular SO was significantly higher in B-CLL cells than in normal B lymphocytes $(\mathrm{p}<0.04)$. Measurements of the intracellular SO generation quantum yield after PDT was done by fluorometry quantitative analysis of photooxidation reactions either using DPBF as the quencher or
SOSG as a fluorescent probe for singlet oxygen, as previously described. B-CLL cells as well as normal B lymphocytes when incubated during two hours with SOSG and observed under fluorescent microscopy were clearly penetrated by this fluorescent probe (Fig 4). The measurement of the intracellular fluorescence spectra of SOSG in the presence of $0.5 \% \mathrm{Mn}$ doped $\mathrm{ZnO}$ NPs inside B-CLL cells and normal B lymphocytes was possible using our described method and recording its changes every minute up to 7 minutes upon irradiation. A selective increase in the intensity of fluorescence of SOSG specially in B-CLL cells as a result of the larger production of intracellular SO induced by the action of light when these $0.5 \% \mathrm{Mn}$ doped $\mathrm{ZnO}$ NPs have already penetrated these cells was recoreded. SO quantum yields were determined with the graph of time dependent of SOSG in the presence of NPs inside cells after PDT . Quantitative comparison of the intracellular SO generation between normal lymphocytes and B-CLL cells, both treated with $\mathrm{Mn} 0.5 \%$ doped $\mathrm{ZnO}$ NPs and PDT, using this SOSG fluorescent probe, showed a significant increased in $\mathrm{SO}$ generation in malignat leukemic cells rather than in normal ones $(p<0.04)$ (fig 5 $\mathrm{a}$ and $\mathrm{b}$ ). The quantum yield was calculated using equation $1^{58}$ and it was 0.88 in B-CLL cells and 0.49 in normal lymphocytes using SOSG as a fluorescent probe for SO, being this difference significant $(\mathrm{p}<0.04)$ (Fig 5 a). In the equation $1 \Phi \Delta$ sample $=\Phi \Delta$ ref where $\Phi \Delta$ ref is SO quantum yield of Rose Bengal (RB), and Ksample as well as Kreference are the slopes of the plot of the timedependent increase of SOSG, expressed as the increase of fluorescence at $526 \mathrm{~nm}$ of the measured of the $\mathrm{Mn} 0.5 \%$ doped $\mathrm{ZnO}$ NPs and the RB, respectively. The other method used to calculate the production of intracellular SO was that in which DPBF performed as the chemical quencher in a decomposition reaction. In the analysis of DPBF oxidation by SO, Ksample andKreference are the slopes of the plot of the time-dependent decomposition of DPBF,expressed as the decrease of fluorescence at 453 $\mathrm{nm}$ of the measured $\mathrm{Mn} 0.5 \%$ doped $\mathrm{ZnO}$ NPs and the $\mathrm{RB}$, respectively. In this way SO production was significantly higher in B-CLL cells compared to normal lymphocytes when both types of cells were treated with NPs and PDT $(p<0.03)^{46,58,59}$ (Fig 6 a and b). Fluorescence spectra photo-oxidation of DPBF in the presence of Mn $0.5 \%$ doped $\mathrm{ZnO}$ NPs inside B-CLL cells showed that DPBF reacts with $\mathrm{SO}$, causing a progressive decrease in the intensity of the quencher. This decomposition of DPBF by SO produced by the use of $\mathrm{RB}$ and $\mathrm{Mn}$ 0.5\% doped ZnONPs in B-CLL cells was a time dependent phenomenon and again there was an increased production of intracellular SO much higher in B-CLL cells than in normal lymphocytes when PDT was delivered $(\mathrm{p}<0.03)$ (fig $6 \mathrm{a}$ and $\mathrm{b}$ ). The quantum yield of SO for B-CLL cells was 0.21 and 0.10 for normal lymphocytes using DPBF as the chemical quencher. Then it is clear that a similar phenomenon was observed in both cases when SOSG or DPBF were used respectively. $\mathrm{SO}$ production was found to be increased both in normal and B-CLL cells when cultured with $0.5 \%$ doped $\mathrm{ZnO}$ 
NPs and laser irradiated, but this increased in SO production was always significantly higher in B-CLL cells compared to normal lymphocytes . This intracellular increased of SO production correlated well with cell mortality as it will be described later. After 24 hours in culture, both healthy $(\mathrm{H})$ and leukemia (L) cells without NPs, had a spontaneous cell death of 5 and $20 \%$ respectively (fig 2). Cell irradiation with lasers showed no statistical difference in terms of apoptosis or mortality in both cell populations at this time, when no NPs were used. However, when cultured during the same period of time, but exposed to $\mathrm{Zn}$ NPs, B-CLL cells without irradiation, showed an important lost of viability specially if culturing time is prolonged to 48 hours. Percentages of cytotoxicity increased significantly with PDT at 24 and 48 hours in B-CLL cells cultured with NPs . Cytotoxicity levels produced by each of the NPs described before on B-CLL cells compared to that on normal B lymphocytes at 24 and 48 hours with and without laser irradiation, was in all cases significantly higher (Fig 2). At the $0.2 \mathrm{mg} / \mathrm{ml}$ concentration, NP2 (Mn doped $0.5 \% \mathrm{ZnO}$ NPs) was the most effective NP in relation to killing activity of B-CLL cells while having a minimum effect on normal $\mathrm{B}$ lymphocytes . Mn doped $0.5 \% \mathrm{ZnO}$ NPs effectively eliminated the largest amount of fludarabine-resistant BCLL cells with almost no lost produced in the viability of normal healthy lymphocytes. Maximum increased in mortality of B-CLL cells was achieved with NPs2 at 48 hours when PDT was applied. Apoptosis levels for irradiated and non-irradiated cells cultured with NPs 2 at 24 and 48 hs detected by flow cytometric analysis (annexin V/PI double staining) was always significantly higher in B-CLL cells compared to normal lymphocytes $(\mathrm{p}<0.01)$ (Fig 7). Apoptotic normal B lymphocytes and B-CLL cells at 24 hours cultured with NPs2 were 14 and $49 \%$, while these percentages moved up after laser irradiation (PDT) to 28 and $90 \%(\mathrm{p}<0.01)$ respectively (Fig 7). Comparison of the mean IC50 of Mn $0.5 \%$ doped $\mathrm{ZnO}$ on B-CLL cells $(\mathrm{n}=5)$ and normal lymphocytes ( $\mathrm{n}$ $=5$ ) clearly showed a significant difference when NPs2 were used to treat B-CLL cells $(\mathrm{p}<0.04)$. Fludarabine resistant B-CLL cells were clearly much more sensitive to NPs2, with an IC50 value of $0.1 \mathrm{mg} / \mathrm{ml}$ while normal lymphocytes had a value a lot above and significantly higher for that same NP2 $(\mathrm{p}<0.04)$ (Fig 8). MTT assays comparing the action of NPs on the mortality of primary B-CLL cells isolated from the blood samples of the 5 CLL patients (L), that were considered clinically Fludarabine resistant with un-mutated Ig VH to that of normal B lymphocytes from healthy subjects $(\mathrm{H})$, clearly showed that the dose dying response to NPs2 in the Fludarabine resistant B-CLL cells was significantly greater than that observed in normal lymphocytes $(\mathrm{p}<0.01)$ (Fig 7). SO production was both found to increase in normal and B-CLL cells when cultured with NPs2, this increase in SO production was significantly higher in B-CLL cells compare to normal lymphocytes $(\mathrm{p}<0.03)$. No dosable free ion $\mathrm{Zn}$ was found in the ultrapure water with NPs2 after 72 hours of incubation. Tests of cytotoxicity with the possible amount of free ion
$\mathrm{Zn}$ that could have been determined in these measurements were not further necessary as no free $\mathrm{Zn}$ was detected at all in the analyzed ultrapure water.

\section{CONCLUSION}

Metal NPs, could be an optional effective and specific treatment for drug resistant forms of $\mathrm{B}-\mathrm{CLL}^{13,60}$. We produced and tested a variety of metal Zn NPs of which one made of $0.5 \%$ Manganese Doped Zinc Oxide $(0.5 \%$ Mn-doped $\mathrm{ZnO}$ ) was finally selected for further characterization and testing as it had the best killing activity in vitro for fludarabine resistant and un-mutated Ig VH B-CLL cells, specially when combined with PDT. Mn-doped ZnO NPs have distinct effects on cell viability via killing of B-CLL cells with low toxicity to normal lymphocytes. These NPs induced a predominant process of autophagy leading to massive death of B-CLL cells related to a higher production of $\mathrm{SO}^{61,62}$. This type of NPs could increase selectively and rapidly, just by themselves, the intracellular levels of SO in B-CLL cells conducting them to an autophagyc death program that could irreversibly kill them easily but very strongly when delivered with PDT. Using this kind of treatment, B lymphocytes, persist mostly alive and not harmed at all, either by these NPs, PDT, or its combination, as it has been said here. We have seen that very small variations of intracellular SO concentrations in leukemic cells, could execute and accelerate these deadly programs in these therapy resistant cells ${ }^{13,14}$, being this mechanism potentiated and increased by the concomitant delivery of PDT, rendering normal cells almost untouched. Our intracellular SO measurement method proved to be good enough, inexpensive and quite simple to perform that it could easily be introduced soon as a routine diagnostic tool. We investigated the mechanisms of cell death during PDT using fluorescence microscopy and imaging and performing fluorometric measurements to help in the design of better treatments for resistant forms of B-CLL. We can envision external devices for blood irradiation by PDT after NPs treatment, or even though "intelligent" $\mathrm{ZnO}$ NPs with self assemblies for energy discharge and light emission from the same NPs or even "hybrids" of biodegradable nanoparticles coated with specific monoclonal antibodies and loaded with ZnO NPS . As this therapy seems to be very specific to fludarabine resistant B-CLL cells, with almost no damage made to normal lymphocytes, it could contribute in the near future as a new innovative targeted strategy to be delivered in the clinical setting, for the definitive benefit not only of these bad prognostic patients but also for all the other indolent lymphomas as well as other types of cancer.

\section{CONFLICT OF INTEREST}

This work was supported by The National Science Foundation under Grant No. HRD 0833112 University of Puerto Rico, Mayaguez Campus, Nanotechnology Center for Biomedical, Environmental, and Sustainability Applications (UPRM CREST Program).

\section{REFERENCES}


1. C. SHERR, "Principles of Tumor Suppression," Cell, vol. 116, no. 2, pp. 235-246, Jan. 2004.

2. M. Palma, P. Kokhaei, J. Lundin, a Choudhury, H. Mellstedt, and a Osterborg, "The biology and treatment of chronic lymphocytic leukemia.," Ann. Oncol., vol. 17 Suppl 1, pp. x144-54, Sep. 2006.

3. J. C. Byrd, T. S. Lin, and M. R. Grever, "Treatment of relapsed chronic lymphocytic leukemia: old and new therapies.," Seminars in oncology, vol. 33, no. 2. pp. 210-9, Apr-2006.

4. J. H. Goldie and A. J. Coldman, "A mathematic model for relating the drug sensitivity of tumors to their spontaneous mutation rate.," Cancer Treat. Rep., vol. 63, no. 11-12, pp. 1727-33, 1979.

5. J. H. Goldie and A. J. Coldman, "A model for tumor response to chemotherapy: an integration of the stem cell and somatic mutation hypotheses.," Cancer Invest., vol. 3, no. 6, pp. 553-64, Jan. 1985.

6. B. Turgut, O. Vural, F. S. Pala, G. E. Pamuk, K. Tabakcioglu, M. Demir, S. Ongören, T. Soysal, and C. Algünes, " $17 \mathrm{p}$ Deletion is associated with resistance of B-cell chronic lymphocytic leukemia cells to in vitro fludarabine-induced apoptosis.," Leuk. Lymphoma, vol. 48, pp. 311-20, 2007.

7. A. Rosenwald, E. Y. Chuang, R. E. Davis, A. Wiestner, A. a Alizadeh, D. C. Arthur, J. B. Mitchell, G. E. Marti, D. H. Fowler, W. H. Wilson, and L. M. Staudt, "Fludarabine treatment of patients with chronic lymphocytic leukemia induces a p53dependent gene expression response.," Blood, vol. 104, no. 5, pp. 1428-34, Sep. 2004.

8. M. R. Grever, D. M. Lucas, G. W. Dewald, D. S. Neuberg, J. C. Reed, S. Kitada, I. W. Flinn, M. S. Tallman, F. R. Appelbaum, R. a Larson, E. Paietta, D. F. Jelinek, J. G. Gribben, and J. C. Byrd, "Comprehensive assessment of genetic and molecular features predicting outcome in patients with chronic lymphocytic leukemia: results from the US Intergroup Phase III Trial E2997.," J. Clin. Oncol., vol. 25, no. 7, pp. 799-804, Mar. 2007.

9. S. a Parikh, K. G. Rabe, N. E. Kay, T. G. Call, W. Ding, S. M. Schwager, D. a Bowen, M. Conte, D. F. Jelinek, S. L. Slager, and T. D. Shanafelt, "Chronic lymphocytic leukemia in young $(<=55$ years $)$ patients: a comprehensive analysis of prognostic factors and outcomes.," Haematologica, vol. 99, no. 1, pp. 140-7, Jan. 2014.

10. T. S. Lin, M. Moran, M. Lucas, S. Waymer, S. Jefferson, D. B. Fischer, M. R. Grever, and J. C. Byrd, "Antibody therapy for chronic lymphocytic leukemia: a promising new modality.," Hematol. Oncol. Clin. North Am., vol. 18, no. 4, pp. 895-913, ix-x, Aug. 2004.

11.L. R. Martins, P. Lúcio, A. Melão, I. Antunes, B. A. Cardoso, R. Stansfield, M. T. S. Bertilaccio, P. Ghia, D. Drygin, M. G. Silva, and J. T. Barata, "Activity of the clinical-stage CK2-specific inhibitor CX-4945 against chronic lymphocytic leukemia.," Leukemia, vol. 28, no. 1, pp. 179-82, Jan. 2014.
12.K. Fischer, P. Cramer, R. Busch, S. Stilgenbauer, J. Bahlo, C. D. Schweighofer, S. Böttcher, P. Staib, M. Kiehl, M. J. Eckart, G. Kranz, V. Goede, T. Elter, A. Bühler, D. Winkler, M. Kneba, H. Döhner, B. F. Eichhorst, M. Hallek, and C.-M. Wendtner, "Bendamustine combined with rituximab in patients with relapsed and/or refractory chronic lymphocytic leukemia: a multicenter phase II trial of the German Chronic Lymphocytic Leukemia Study Group.," J. Clin. Oncol., vol. 29, no. 26, pp. 3559-66, Sep. 2011.

13.E. Y. O. and S. A. R. Marina A. Orlova, "Effect of 67Zn-Nanoparticles on Leukemic Cells and Normal Lymphocytes," Br. J. Med. Med. Res., vol. 2, pp. 2130, 2012.

14.D. Trachootham, H. Zhang, W. Zhang, L. Feng, M. Du, Y. Zhou, Z. Chen, H. Pelicano, W. Plunkett, W. G. Wierda, M. J. Keating, and P. Huang, "Effective elimination of fludarabine-resistant CLL cells by PEITC through a redox-mediated mechanism.," Blood, vol. 112, no. 5, pp. 1912-22, Sep. 2008.

15. C. Hanley, J. Layne, A. Punnoose, K. M. Reddy, I. Coombs, A. Coombs, K. Feris, and D. Wingett, "Preferential killing of cancer cells and activated human T cells using ZnO nanoparticles.," Nanotechnology, vol. 19, no. 29. p. 295103, 23-Jul2008.

16.E. Ricci-Júnior and J. M. Marchetti, "Zinc(II) phthalocyanine loaded PLGA nanoparticles for photodynamic therapy use.," Int. J. Pharm., vol. 310, no. 1-2, pp. 187-95, Mar. 2006.

17.D. K. Chatterjee, L. S. Fong, and Y. Zhang, "Nanoparticles in photodynamic therapy: an emerging paradigm.," Adv. Drug Deliv. Rev., vol. 60, no. 15, pp. 1627-37, Dec. 2008.

18. A. C. S. Samia, X. Chen, and C. Burda, "Semiconductor quantum dots for photodynamic therapy.," J. Am. Chem. Soc., vol. 125, no. 51, pp. 15736-7, Dec. 2003.

19.E. Mansilla, G. Marin, and L. Núñez, "Present and Future Application of Nanoparticle Based Therapies in B-Chronic Lymphocytic Leukemia (B-CLL)," in intechopen.com, no. 3, 2012, pp. 431-448.

20.E. Mansilla, G. H. Marin, L. Nuñez, H. Drago, F. Sturla, C. Mertz, L. Rivera, T. Ichim, N. Riordan, and C. Raimondi, "The lysosomotropic agent, hydroxychloroquine, delivered in a biodegradable nanoparticle system, overcomes drug resistance of Bchronic lymphocytic leukemia cells in vitro.," Cancer Biother. Radiopharm., vol. 25, no. 1, pp. 97-103, Feb. 2010.

21.G. H. Marin, E. Mansilla, G. Larsen, and P. Macor, "Exploratory Study on the Effects of Biodegradable Nanoparticles with Drugs on Malignant B Cells and on a Human/Mouse Model of Burkitt Lymphoma | BenthamScience," Curr. Clin. Pharmacol., vol. 5, no. 4, pp. 246-250, 2013.

22. Y.-N. Wu, D.-H. Chen, X.-Y. Shi, C.-C. Lian, T.-Y. Wang, C.-S. Yeh, K. R. Ratinac, P. Thordarson, F. Braet, and D.-B. Shieh, "Cancer-cell-specific cytotoxicity of non-oxidized iron elements in iron 
core-gold shell NPs.," Nanomedicine, vol. 7, no. 4, pp. 420-7, Aug. 2011.

23. M. J. Akhtar, M. Ahamed, S. Kumar, M. M. Khan, J. Ahmad, and S. a Alrokayan, "Zinc oxide nanoparticles selectively induce apoptosis in human cancer cells through reactive oxygen species.," Int. $J$. Nanomedicine, vol. 7, pp. 845-57, Jan. 2012.

24. S. Ostrovsky, G. Kazimirsky, A. Gedanken, and C. Brodie, "Selective cytotoxic effect of $\mathrm{ZnO}$ nanoparticles on glioma cells," Nano Res., vol. 2, no. 11, pp. 882-890, Nov. 2009.

25. H. Zhang, B. Chen, H. Jiang, C. Wang, H. Wang, and $\mathrm{X}$. Wang, "A strategy for $\mathrm{ZnO}$ nanorod mediated multi-mode cancer treatment.," Biomaterials, vol. 32, no. 7, pp. 1906-14, Mar. 2011.

26. J. Li, D. Guo, X. Wang, H. Wang, H. Jiang, and B. Chen, "The Photodynamic Effect of Different Size $\mathrm{ZnO}$ Nanoparticles on Cancer Cell Proliferation In Vitro.," Nanoscale research letters, vol. 5, no. 6. pp. 1063-71, Jan-2010.

27.D. Bechet, P. Couleaud, C. Frochot, M.-L. Viriot, F. Guillemin, and M. Barberi-Heyob, "Nanoparticles as vehicles for delivery of photodynamic therapy agents.," Trends Biotechnol., vol. 26, no. 11, pp. 61221, Dec. 2008.

28. R. T. M. Boudreau, D. M. Conrad, and D. W. Hoskin, "Differential involvement of reactive oxygen species in apoptosis caused by the inhibition of protein phosphatase 2A in Jurkat and CCRF-CEM human Tleukemia cells.," Exp. Mol. Pathol., vol. 83, no. 3, pp. 347-56, Dec. 2007.

29. H. Pelicano, L. Feng, Y. Zhou, J. S. Carew, E. O. Hileman, W. Plunkett, M. J. Keating, and P. Huang, "Inhibition of mitochondrial respiration: a novel strategy to enhance drug-induced apoptosis in human leukemia cells by a reactive oxygen species-mediated mechanism.," J. Biol. Chem., vol. 278, no. 39, pp. 37832-9, Sep. 2003.

30.A. Manke, L. Wang, and Y. Rojanasakul, "Mechanisms of nanoparticle-induced oxidative stress and toxicity.," Biomed Res. Int., vol. 2013, p. 942916 , Jan. 2013.

31. W. Lin, Y. Xu, C.-C. Huang, Y. Ma, K. B. Shannon, D.-R. Chen, and Y.-W. Huang, "Toxicity of nano- and micro-sized $\mathrm{ZnO}$ particles in human lung epithelial cells," J. Nanoparticle Res., vol. 11, no. 1, pp. 25-39, Jun. 2008.

32. A. Gollmer, J. Arnbjerg, F. H. Blaikie, B. W. Pedersen, T. Breitenbach, K. Daasbjerg, M. Glasius, and P. R. Ogilby, "Singlet Oxygen Sensor Green ${ }^{\circledR}$ : photochemical behavior in solution and in a mammalian cell.," Photochem. Photobiol., vol. 87, no. 3, pp. 671-9, 2011.

33. C. Schweitzer and R. Schmidt, "Physical mechanisms of generation and deactivation of singlet oxygen.," Chem. Rev., vol. 103, no. 5, pp. 1685-757, May 2003.

34. A. P. Castano, P. Mroz, and M. R. Hamblin, "Photodynamic therapy and anti-tumour immunity.," Nat. Rev. Cancer, vol. 6, no. 7, pp. 535-45, Jul. 2006.
35. R. C. DeRosa, M, "Photosensitized singlet oxygen and its applications," Coord. Chem. Rev., vol. 233-234, no. null, pp. 351-371, Nov. 2002.

36. K. E. McCloskey, J. J. Chalmers, and M. Zborowski, "Magnetic cell separation: characterization of magnetophoretic mobility.," Anal. Chem., vol. 75, no. 24, pp. 6868-74, Dec. 2003.

37.H. Abts, M. Emmerich, S. Miltenyi, A. Radbruch, and H. Tesch, "CD20 positive human B lymphocytes separated with the magnetic cell sorter (MACS) can be induced to proliferation and antibody secretion in vitro," J. Immunol. Methods, vol. 125, no. 1-2, pp. 19-28, Dec. 1989.

38. G. P. Sims and P. E. Lipsky, "Isolation of human B cell populations.," Curr. Protoc. Immunol., vol. Chapter 7, p. Unit 7.5, Dec. 2006.

39. P. Bihari, M. Vippola, S. Schultes, M. Praetner, A. G. Khandoga, C. a Reichel, C. Coester, T. Tuomi, M. Rehberg, and F. Krombach, "Optimized dispersion of nanoparticles for biological in vitro and in vivo studies.," Part. Fibre Toxicol., vol. 5, p. 14, Jan. 2008.

40.R. Ullah and J. Dutta, "Photocatalytic degradation of organic dyes with manganese-doped $\mathrm{ZnO}$ nanoparticles.," J. Hazard. Mater., vol. 156, no. 1-3, pp. 194-200, Aug. 2008.

41.S. Jana, B. B. Srivastava, and N. Pradhan, "Correlation of Dopant States and Host Bandgap in Dual-Doped Semiconductor Nanocrystals," J. Phys. Chem. Lett., vol. 2, no. 14, pp. 1747-1752, Jul. 2011.

42. M. W. Porambo, H. R. Howard, and A. L. Marsh, "Dopant Effects on the Photocatalytic Activity of Colloidal Zinc Sulfide Semiconductor Nanocrystals for the Oxidation of 2-Chlorophenol," J. Phys. Chem. $C$, vol. 114, no. 3, pp. 1580-1585, Jan. 2010.

43.L. Gan, B. Liu, C. Chew, S. Xu, and S. Chua, "Enhanced photoluminescence and characterization of Mn-doped ZnS nanocrystallites synthesized in microemulsion," Langmuir, vol. 7463, no. 20, pp. 6427-6431, 1997.

44. M. Geszke, M. Murias, L. Balan, G. Medjahdi, J. Korczynski, M. Moritz, J. Lulek, and R. Schneider, "Folic acid-conjugated core/shell $\mathrm{ZnS}: \mathrm{Mn} / \mathrm{ZnS}$ quantum dots as targeted probes for two photon fluorescence imaging of cancer cells.," Acta Biomater., vol. 7, no. 3, pp. 1327-38, Mar. 2011.

45.D. Jiang, L. Cao, W. Liu, G. Su, H. Qu, Y. Sun, and B. Dong, "Synthesis and Luminescence Properties of Core/Shell ZnS:Mn/ZnO Nanoparticles.," Nanoscale Res. Lett., vol. 4, no. 1, pp. 78-83, Jan. 2009.

46. D. Tada, L. Vono, E. Duarte, and R. Itri, "Methylene blue-containing silica-coated magnetic particles: a potential magnetic carrier for photodynamic therapy," Langmuir, no. 21, pp. 8194-8199, 2007.

47. S. Dumas, J.-C. Leprêtre, a. Lepellec, a. Darmanyan, and P. Jardon, "Reactivity of the photo excited forms of Hypericin, Hypocrellin A, Hypocrellin B and methylated Hypericin towards molecular oxygen," $J$. Photochem. Photobiol. A Chem., vol. 163, no. 3, pp. 297-306, May 2004. 
48.H. Shinohara, O. Tsaryova, G. Schnurpfeil, and D. Wöhrle, "Differently substituted phthalocyanines: Comparison of calculated energy levels, singlet oxygen quantum yields, photo-oxidative stabilities, photocatalytic and catalytic activities," J. Photochem. Photobiol. A Chem., vol. 184, no. 1-2, pp. 50-57, Nov. 2006.

49.F. Wilkinson, W. Helman, and A. Ross, "Quantum yields for the photosensitized formation of the lowest electronically excited singlet state of molecular oxygen in solution," J. Phys. ..., pp. 1-29, 1993.

50. J. S. Miller, "Rose bengal-sensitized photooxidation of 2-chlorophenol in water using solar simulated light.," Water Res., vol. 39, no. 2-3, pp. 412-22, 2005.

51.C. C. Winterbourn, "The challenges of using fluorescent probes to detect and quantify specific reactive oxygen species in living cells.," Biochim. Biophys. Acta, vol. 1840, no. 2, pp. 730-8, Mar. 2014.

52.V. Mote, J. Dargad, and B. Dole, "Effect of Mn Doping Concentration on Structural, Morphological and Optical Studies of ZnO Nano-particles," Nanosci. Nanoeng., vol. 1, no. 2, pp. 116-122, 2013.

53.S. Nagarajan and K. Arumugam Kuppusamy, "Extracellular synthesis of zinc oxide nanoparticle using seaweeds of gulf of Mannar, India.," $J$. Nanobiotechnology, vol. 11, no. 1, pp. 2-11, Jan. 2013.

54.R. Venkatramana, R. Sankana, and K. Pramoda, "Synthesis , Structural , Optical Properties and Antibacterial activity of co- doped ( $\mathrm{Ag}, \mathrm{Co}$ ) $\mathrm{ZnO}$ Nanoparticles," Res. J. Mater. Sci., vol. 1, no. 1, pp. 11-20, 2013.

55.D. Glick, S. Barth, and K. F. Macleod, "Autophagy: cellular and molecular mechanisms.," The Journal of pathology, vol. 221, no. 1. pp. 3-12, May-2010.
56. S. Hackenberg, A. Scherzed, A. Gohla, A. Technau, K. Froelich, C. Ginzkey, C. Koehler, M. Burghartz, R. Hagen, and N. Kleinsasser, "Nanoparticle-induced photocatalytic head and neck squamous cell carcinoma cell death is associated with autophagy.," Nanomedicine (Lond)., vol. 9, no. 1, pp. 21-33, Jan. 2014.

57.K.-N. Yu, T.-J. Yoon, A. Minai-Tehrani, J.-E. Kim, S. J. Park, M. S. Jeong, S.-W. Ha, J.-K. Lee, J. S. Kim, and M.-H. Cho, "Zinc oxide nanoparticle induced autophagic cell death and mitochondrial damage via reactive oxygen species generation.," Toxicol. In Vitro, vol. 27, no. 4, pp. 1187-95, Jun. 2013.

58. M. Kostka, P. Zimcik, M. Miletin, P. Klemera, K. Kopecky, and Z. Musil, "Comparison of aggregation properties and photodynamic activity of phthalocyanines and azaphthalocyanines," $J$. Photochem. Photobiol. A Chem., vol. 178, no. 1, pp. 16-25, Feb. 2006.

59. K. Nakamura, K. Ishiyama, H. Ikai, T. Kanno, K. Sasaki, and Y. Niwano, "Reevaluation of analytical methods for photogenerated singlet oxygen," vol. 49, no. 2, pp. 87-95, 2011.

60.D. Guo, C. Wu, H. Jiang, Q. Li, X. Wang, and B. Chen, "Synergistic cytotoxic effect of different sized $\mathrm{ZnO}$ nanoparticles and daunorubicin against leukemia cancer cells under UV irradiation.," J. Photochem. Photobiol. B., vol. 93, no. 3, pp. 119-26, Dec. 2008.

61.D. Guo, H. Bi, B. Liu, Q. Wu, D. Wang, and Y. Cui, "Reactive oxygen species-induced cytotoxic effects of zinc oxide nanoparticles in rat retinal ganglion cells.," Toxicol. In Vitro, vol. 27, no. 2, pp. 731-8, Mar. 2013.

62.P. T. Schumacker, "Reactive oxygen species in cancer cells: live by the sword, die by the sword.," Cancer Cell, vol. 10, no. 3, pp. 175-6, Sep. 2006. 